\title{
Neutron Detection with a \\ Cryogenic Spectrometer
}

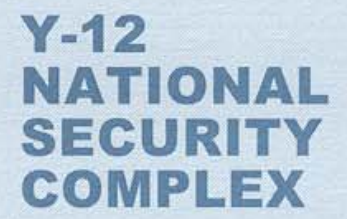

$\mathrm{Y}-12$

NATIONAL

SECURITY

COMPLEX

\author{
Z. W. Bell, V. E. Lamberti, \\ D. A. Carpenter, S. S. Cristy \\ Y-12 National Security Complex \\ P. O. Box 2009 \\ Oak Ridge, TN 37831
}

\author{
A. Burger \\ Fisk University \\ 240 Dubois Hall, $100017^{\text {th }}$ Avenue, \\ Nashville, TN 37208-3051 \\ Thomas Niedermayr, I. Dragos Hau \\ Simon E. Labov, Stephan Friedrich \\ Lawrence Livermore National Laboratory \\ 7000 East Avenue L-270, Livermore, CA 94550 \\ Brian F. Woodfield \\ Brigham Young University \\ Department of Chemistry and Biochemistry \\ Provo, UT 84602
}

Date of Issue: June 23, 2003 


\section{DISCLAIMER}

This report was prepared as an account of work sponsored by an agency of the United States Government. Neither the United States Government nor any agency thereof, nor any of their employees, makes any warranty, express or implied, or assumes any legal liability or responsibility for the accuracy, completeness, or usefulness of any information, apparatus, product, or process disclosed, or represents that its use would not infringe privately owned rights. Reference herein to any specific commercial product, process, or service by trade name, trademark, manufacturer, or otherwise, does not necessarily constitute or imply its endorsement, recommendation, or favoring by the United States Government or any agency thereof. The views and opinions of authors expressed herein do not necessarily state or reflect those of the United States Government or any agency thereof.

\section{COPYRIGHT NOTICE}

The submitted manuscript has been authorized by a contractor of the U. S. Government under contract DE-AC05-00OR-22800. Accordingly, the U. S. Government retains a paid-up, nonexclusive, irrevocable, worldwide license to publish or reproduce the published form of this contribution, prepare derivative works, distribute copies to the public, and perform publicly and display publicly, or allow others to do so, for U. S. Government purposes. 


\title{
Neutron Detection with a Cryogenic Spectrometer
}

\author{
Z. W. Bell, V. E. Lamberti, \\ D. A. Carpenter, S. S. Cristy \\ Y-12 National Security Complex \\ P. O. Box 2009 \\ Oak Ridge, TN 37831
}

\author{
A. Burger \\ Fisk University \\ 240 Dubois Hall, $100017^{\text {th }}$ Avenue, \\ Nashville, TN 37208-3051 \\ Thomas Niedermayr, I. Dragos Hau \\ Simon E. Labov, Stephan Friedrich \\ Lawrence Livermore National Laboratory \\ 7000 East Avenue L-270, Livermore, CA 94550 \\ Brian F. Woodfield \\ Brigham Young University \\ Department of Chemistry and Biochemistry \\ Provo, UT 84602
}

Date of Issue: June 23, 2003

\author{
Prepared by the \\ Y-12 National Security Complex \\ P. O. Box 2009, \\ Oak Ridge, Tennessee 37831-8169 \\ managed by \\ BWXT Y-12 L.L.C. \\ for the \\ U.S. DEPARTMENT OF ENERGY \\ under contract DE-AC05-00OR-22800
}


Neutron Detection with a Cryogenic Spectrometer

Z. W. Bell, D. A. Carpenter, S. S. Cristy, V. E. Lamberti,

Y-12 National Security Complex, P.O. Box 2009, Oak Ridge TN 37831-8084, bellzw@y12.doe.gov

A. Burger,

Fisk University, 240 Dubois Hall, 1000 17th Ave N, Nashville, TN 37208-3051

Brian F. Woodfield,

Brigham Young University, Department of Chemistry and Biochemistry, Provo, UT 84602

Thomas Niedermayr, I. Dragos Hau, Simon E. Labov, Stephan Friedrich

Lawrence Livermore National Laboratory, 7000 East Ave, P.O. Box 808, Livermore, CA 94550

\section{INTRODUCTION}

Cryogenic calorimeters are used for $\mathrm{x}$-ray detection because of their exquisite energy resolution[1] and have found application in x-ray astronomy, and the search for dark matter.[3] These devices operate by detecting the heat pulse produced by ionization in an absorber cooled to temperatures below $1 \mathrm{~K}$. Such temperatures are needed to lower the absorber's heat capacity to the point that the deposition of even a few $\mathrm{eV}$ results in a measurable temperature excursion.

Typical absorbers for dark matter measurements are massive Si or Ge crystals, and, with $\mathrm{Ge}$, have achieved a resolution of $650 \mathrm{eV}$ at $10 \mathrm{keV}[4]$. Chow, et al.,[5] report the

measurement of the $60 \mathrm{keV}$ emission from ${ }^{241} \mathrm{Am}$ with $230 \mathrm{eV}$ resolution using a superconducting tin absorber. Cunningham, et al.,[6], also using a superconducting tin absorber, have recently reported a four-fold improvement over Chow.

With such results being reported from the $\mathrm{x}$ and gamma ray world it is natural to examine the possibilities for cryogenic neutron spectroscopy. Such a detector would operate by detecting the heat pulses caused by neutron capture and scattering. To date, ${ }^{6} \mathrm{LiF}$ has been the absorber of choice because relatively large crystals can be grown, and it is an insulating material with low heat capacity. Silver[2] reports the fabrication of a ${ }^{6} \mathrm{LiF}$ spectrometer operating at $328 \mathrm{mK}$ and achieving a resolution of $39 \mathrm{keV}$. De Marcillac[7] reports the fabrication of a spectrometer operating at $80 \mathrm{mK}$ and achieving $16 \mathrm{keV}$ resolution when bombarded with $5 \mathrm{MeV}$ alpha particles.
In this paper, we report preliminary results with a $\mathrm{TiB}_{2}$ absorber exposed to thermal neutrons. In contrast to lithium, whose chemistry selects for $\mathrm{LiF}$ as the absorber, boron offers a rich chemistry from which to select materials with high boron content. We will discuss the considerations governing the choice of absorber material as well as the basic considerations needed to understand a cryogenic spectrometer. The capture and scattering reactions in boron and lithium were modeled with MCNP. The modeling results and methods of analysis applicable to lithium- and boronbased spectrometers will be given.

\section{CRYOGENIC SPECTROMETER}

The cryogenic spectrometer consists of an absorber mounted on a Mo-Cu transition edge sensor (TES), in turn mounted on a silicon nitride membrane in contact with a cold bath. The cold bath is realized as a two-stage adiabatic demagnetization refrigerator (ADR). The ADR used two paramagnetic salts in contact with thermally isolated nested cold fingers to hold the absorber near $100 \mathrm{mK}$.[8]

The TES consists of alternating layers of Mo and $\mathrm{Cu}$, the number and thicknesses of which determine the temperature at which it switches from the superconducting state to normalconduction. However, the transition occurs over a temperature range measured in $\mathrm{mK}$, and is nearly linear over a portion of that range. Consequently, for heat pulses in an appropriately sized absorber, the change in resistance is proportional to the deposited energy.

A weak thermal link separates the TES and membrane, and determines the rate at which heat 
is drawn from the absorber into the cold bath. The time constant for the instrument is approximately $80 \mathrm{~ms}$ and is a determined by the thermal conductivity of the thermal links and the heat capacity of the absorber.

\section{SELECTION OF ABSORBER}

The energy, $Q+E_{n}$, involved in neutron absorption is measured in $\mathrm{MeV}$. To achieve a temperature change less than $1 \mathrm{mK}$, it is necessary for the absorber to have a heat capacity of about $1 \mathrm{~nJ} / \mathrm{K}$.

In the present design, the silicon nitride membrane limits the mass of the absorber to a few milligrams. At $120 \mathrm{mK}$ (the operating temperature of the TES), the heat capacities of milligram pieces of $\mathrm{LiF}$, and insulating, semiand superconducting boron compounds are too small. Consequently, normal-conducting boron compounds were evaluated. It was found that $\mathrm{TiB}_{2}$ has reasonably high boron content and measurement of the heat capacity confirmed its suitability.

\section{MEASUREMENT OF NEUTRONS}

The TES with the $\mathrm{TiB}_{2}$ specimen mounted on it were mounted in the spectrometer and exposed to neutrons from a $10^{7} \mathrm{n} / \mathrm{s}{ }^{252} \mathrm{Cf}$ source placed within a U-shaped moderator/safety shield constructed from bricks of pressed boric acid powder. The spectrometer sat at the open end of the "U." Although boron in the bricks limited the thermal flux available to the detector, the count rate was approximately $0.75 / \mathrm{s}$.

\section{RESULTS}

Pulses were accumulated over the course of 3 hours and sorted according to amplitude. Peaks, approximately in the ratio of $16: 1$, corresponding to the ground state and first excited state of ${ }^{7} \mathrm{Li}$ were observed in the spectrum at 2.31 and $2.8 \mathrm{MeV}$ deposited energy. Fitting the initial unfiltered data determined the FWHM to be $15 \mathrm{keV}$. In subsequent filtered data the resolution improved to $11.3 \mathrm{keV}$ at 2.31 $\mathrm{MeV}$ and $5.3 \mathrm{keV}$ at $2.8 \mathrm{MeV}$. Work to further improve the filtering and resolution is continuing.

It should be noted that the resolution of this type of spectrometer is a function of the operating temperature[5], rather than the deposition energy. Consequently, the same several $\mathrm{keV}$ resolution is expected to be observed with $\mathrm{MeV}$ neutrons as well. The high resolution offered by this instrument opens the door to neutron spectroscopy without recourse to time of flight or unfolding methods. Looking to the future, it would be expected that the spectrometer would be able to distinguish between different fission sources, and between fission and radioactive sources. This may even be possible even in the presence of moderator or shielding.

\section{REFERENCES}

1. K. D. IRWIN, G. C. HILTON, D. A. WOLLMAN, J. M. MARTINIS, Appl. Phys. Lett., 66, 1945 (1996).

2. C. S. SILVER, J. BEEMAN, L. PICCIRILLO, P. T. TIMBIE, J. W. ZHOU, Nucl. Instr. Meth. In Phys. Res. A, 485615 (2002).

3. See, for example, the University of California, Berkeley, web site http://cdms.berkeley.edu for a link to dozens of references.

4. D. S. AKERIB, et al. Nucl. Phys. B (Proc. Suppl.) 7064 (1999).

5. D. T. CHOW, M. A. LINDEMAN, M. F. CUNNINGHAM, M. FRANK, T. W. BARBEE, JR. S. E. LABOV, Nucl. Instr. Meth. In Phys. Res. A, 444196 (2000).

6. M. F. CUNNINGHAM, J. N. ULLOM, T. MYAZAKI, S. E. LABOV, JOHN CLARKE, T. M. LANTING, ADRIAN T. LEE, P. L. RICHARDS, JONGSOO YOON, H SPEILER, App. Phys. Lett., 81 159 (2002).

7. P. DE MARCILLAC, N. CORON, J. LEBLANC, C. BOBIN, I. BERKES, M. DE JESUS, J. P. HADJOUT, L. GONZALEZMESTRES, J. W. ZHOU, Nucl. Instr. Meth. A, 33795 (1993).

8. S. FRIEDRICH, T. NIEDERMAYR, O. DRURY, M. F. CUNNINGHAM, M. L. VAN DEN BERG, J. N. ULLOM, A. LOSHAK, T. FUNK, S. P. CRAMER, J. D. BATTEUX, E. SEE, M. FRANK, S. E. LABOV, Nucl. Instr. Meth. In Phys. Res. A, 4671117 (2001). 